\title{
Penentuan Kriteria Pengukuran Indikator Kinerja Penyelenggaraan Diklat Berbasis Kompetensi Menggunakan Metode Focus Group Discussion
}

\author{
Rohmatulloh $^{1}$, Julian Ambassadur Shiddiq ${ }^{2}$
}

\begin{abstract}
The formulation of performance indicators is good and meaningful must meet the criteria CREAM (clear, relevant, economic, adequate, and monitorable). In practice, it is often found performance indicators can not be applied because it has a variety of interpretations in the criteria of measurement. The problem is discussed using focus group method (FG). The results of the discussion have succeeded in identifying and consensusing the six criteria for measuring the key performance indicators (KPI) for the implementation of competency-based training, ie training needs analysis, syllabus curriculum, modules, training implementation guidelines, evaluation of training, and evaluation of training implementation (satisfaction and learning). The use of the FG method in this study is effective enough to generate many ideas and the participation of internal stakeholders in solving the problem. The success of FG is highly dependent on pre-discussion planning, especially the deepening of the issues studied and the determination of data sources or participants, who understand the issues being discussed.
\end{abstract}

Keywords: Performance indicator, competency-based training, focus group

Abstrak. Perumusan indikator kinerja (IK) yang baik dan bermakna harus memenuhi kriteria CREAM (clear, relevant, economic, adequate, dan monitorable). Dalam prakteknya, seringkali ditemukan masalah IK tidak bisa diterapkan karena memiliki ragam penafsiran dalam kriteria pengukurannya. Permasalahan tersebut dibahas menggunakan metode focus group (FG). Hasil diskusi telah berhasil mengidentifikasi dan mengkonsensuskan enam kriteria pengukuran indikator kinerja utama (IKU) penyelenggaraan diklat berbasis kompetensi yaitu analisis kebutuhan diklat, kurikulum silabus, modul, pedoman penyelenggaraan diklat, evaluasi widyaiswara, dan evaluasi penyelenggaraan diklat (kepuasan dan pembelajaran). Penggunaan metode FG pada penelitian ini cukup efektif untuk membangkitkan banyak ide dan partisipasi pemangku kepentingan internal dalam menyelesaikan masalah. Keberhasilan FG sangat tergantung dari perencanaan sebelum diskusi khususnya pendalaman masalah yang dikaji dan penentuan sumber data (partisipan) yang mengerti permasalahan yang didiskusikan.

Kata Kunci: Indikator kinerja, diklat berbasis kompetensi, focus group.

\section{Pendahuluan}

Indikator adalah variabel kuantitatif atau kualitatif yang memberikan arti sederhana

\footnotetext{
${ }^{1}$ Pusat Pengembangan Sumber Daya Manusia Aparatur, Jalan Cisitu Lama No. 37, Bandung 40135

2 Sekretariat Badan Pengembangan SDM, Energi dan Sumber Daya Mineral, Jl. Jend. Gatot Soebroto Kav. 49, Jakarta 12950

${ }^{1}$ email: rohmatulloh@diklat.esdm.go.id

2 email: julianambassador@diklat.esdm.go.id

Diajukan: 27-05-2017

Disetujui: 25-11-2017
}

dan handal untuk mengukur capaian, merefleksikan perubahan melalui sebuah intervensi atau membantu menilai kinerja organisasi terhadap outcome yang telah dinyatakan. Perumusan indikator kinerja (IK) dilakukan dengan mempertimbangkan kriteria mutu agar diperoleh indikator sesuai kebutuhan organisasi. Indikator yang baik dan bermakna harus memenuhi kriteria mutu CREAM (clear, relevant, economic, adequate, monitorable) (Kusek \& Rist, 2004). Dengan mengunakan kriteria ini, idealnya IK yang telah dirumuskan dapat diimplementasikan dengan baik dan banyak 
memberikan informasi bermakna bagi pengambil keputusan dalam menentukan intervensi perbaikan yang diperlukan untuk meningkatkan kinerja kebijakan, program, dan kegiatan.

Terkait dengan IK yang dirumuskan Badan Diklat ESDM tahun 2015-2019, terdapat beberapa IK yang dalam perumusannya masih memiliki ragam penafsiran oleh pemangku kepentingan internal. Akibatnya pemangku kepentingan melakukan pengukuran dengan kriteria yang berbeda-beda sesuai penafsirannya masingmasing. Penelitian ini bertujuan untuk menentukan perbaikan kriteria pengukuran yang disepakati pemangku kepentingan internal agar dapat menghasilkan IK yang memenuh kriteria CREAM. Fokus IK yang dibahas dalam penelitian ini adalah penyelenggaraan diklat berbasis kompetensi. IK ini merupakan salah satu indikator kinerja utama (IKU) dari enam IKU yang dimilikinya. IKU merepresentasikan seluruh aspek kinerja organisasi yang sangat kritis untuk kesuksesan saat ini dan masa depan organisasi. Karakterisitik IKU adalah ukuran non fnansial, pengukurannya sering, dilakukan oleh pimpinan puncak, pengaruhnya signifikan terhadap IKU dan IK lainnya dalam seluruh perspektif balanced scorecard, dan berpengaruh positif terhadap seluruh aspek kinerja lainnya (Parmenter, 2007).

Demonstrasi penyelesaian masalah penentuan kriteria pengukuran IKU penyelenggaraan diklat berbasis kompetensi melibatkan para pemangku kepentingan internal menggunakan metode focus group (FG). Adapun istilah FG yang digunakan dalam makalah ini adalah focus group discussion (FGD) seperti yang digunakan oleh (Smithson, 2000).

\section{Focus Group Discussion}

Focus group (FG) atau kelompok terarah adalah hanya salah satu teknik penelitian dari banyak teknik lainnya yang melibatkan kelompok seperti nominal group technique (NGT), delphi, brainstorming, synetics, leaderless discussion group (Stewart \& Shamdasani, 1990). Konsep awal FG dapat dilacak dari hasil pekerjaan Merton dan koleganya dari Columbia University pada tahun 1940an yang disebut dengan istilah the focused interview. FG pertama kali diterapkan pada ilmu sosial untuk menyelidiki dinamika sosial, komunikasi persuasif, dan pengaruh media masa sebagai dampak dari upaya propaganda perang dunia kedua. Sampai dengan hari ini, FG merupakan metode kualitatif populer yang digunakan sebagai alat untuk evaluasi program, pemasaran, kebijakan publik, periklanan, komunikasi, peningkatan mutu layanan, dan evaluasi kinerja pegawai (Stewart \& Shamdasani, 1990; Bader \& Rossi, 1998)

Definisi FG adalah interview atau wawancara kelompok terstruktur untuk mengumpulkan pendapat dan pengetahuan tentang topik tertentu dari partisipan terpilih (Bader \& Rossi, 1998). Smithson (2000) mengidentifikasi definisi FG dari para peneliti dan menemukan penekanan FG sebagai metode interview dan diskusi kelompok. Perbedaan keduanya dijelaskan dalam bentuk interaksi instrumen pengumpul data dan sumber data. Interview menekankan interaksi peneliti-partisipan, sedangkan diskusi menekankan interaksi antar partisipan (Smithson, 2000). Salah satu karakteristik FG adalah melibatkan anggota kelompok yang homogen dan pada umumnya melibatkan sebanyak 6 - 12 individu dengan dipandu oleh seorang fasilitator. Namun ukuran besar kecilnya kelompok disesuaikan dengan ruang lingkup isu atau masalah penelitian yang dibahas. Jika penelitiannya kompleks, maka dibutuhkan banyak kelompok FG. Namun jika partisipannya relatif homogen dan pertanyaan penelitiannya sederhana, maka dibutuhkan kelompok yang sedikit. Durasi waktu pelaksanaan sesi diskusi sekitar 90 - 150 menit. Jumlah 
ukuran kelompok juga akan mempengaruhi tingkat keaktifan partisipan. Kelompok yang terlalu kecil akan didominasi oleh satu atau dua anggota individu, sementara kelompok yang terlalu besar sulit untuk dikelola fasilitator dan tingkat keaktifan individu sedikit (Stewart \& Shamdasani, 1990).

Penggunaan FG secara umum untuk memperoleh, menganalisis, dan menyajikan data untuk penyelesaian masalah di berbagai bidang, diantaranya untuk: a) memperoleh informasi latar belakang yang bersifat umum pada topik tertentu, b) membangkitkan hipotesis penelitian, c) merangsang ide baru dan konsep kreatif, d) mendiagnosa potensi masalah pada sebuah program, produk, dan layanan baru, e) membangkitkan impresi pada program, produk, layanan, organisasi, atau objek tertentu lainnya, f) mempelajari cara partisipan menceritakan fenomena yang dapat digunakan untuk memfasilitasi desain kuesioner, instrumen survei, atau instrumen penelitian lainnya, g) menginterpretasikan data hasil penelitian kuantitatif yang telah dilakukan sebelumnya, dan h) memfasilitasi pengambilan keputusan (Stewart \& Shamdasani, 1990; Williams \& Katz, 2001).
Sebagai sebuah metode, FG memiliki berbagai kelebihan dibandingkan metode lainnya sebagai alat mengumpulkan, menganalisis, dan menyajikan data. Namun di sisi lain, FG juga bukan sebuah metode yang dapat menyelesaiakan berbagai masalah tanpa ada keterbatasan yang dimilikinya. Tabel 1 menyajikan berbagai kelebihan dan kekurangan metode FG (Stewart \& Shamdasani, 1990; Bader \& Rossi, 1998).

FG secara tradisional dilakukan melalui tatap muka langsung. Namun dewasa ini dengan berkembangnya teknologi informasi dan komputer, FG dapat dilakukan secara maya (virtual) dengan menggunakan telekonferensi dan video konferensi. Beberapa kelebihan penggunaan FG virtual adalah cepat, mudah, dan murah. Sedangkan kekurangannya adalah memerlukan kompetensi teknis yang tinggi dan sulit membangun hubungan harmonis dan saling percaya (rapprot) (Bader \& Rossi, 1998). Pelaksanaan FG secara tradisional dilakukan melalui tiga tahapan yaitu perencanaan, pelaksanaan, dan evaluasi. Tabel 2 menunjukkan tahapan pelaksanaan FG yang dikembangkan para peneliti.

Tabel 1. Kelebihan dan kekurangan FG

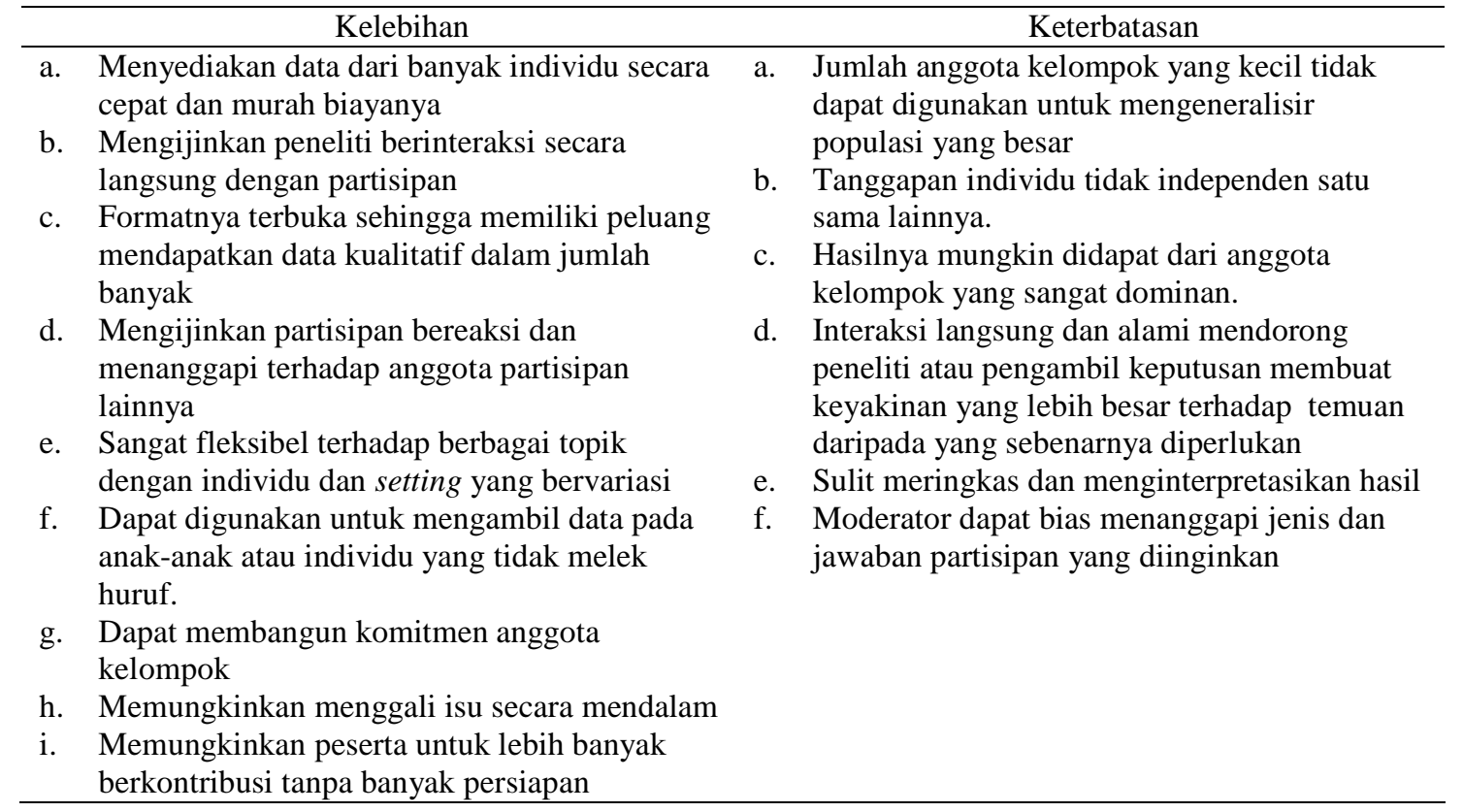


Tabel 2. Tahapan pelaksanaan FG

\begin{tabular}{|c|c|c|c|}
\hline Tahap & (Stewart \& Shamdasani, 1990) & (Bader \& Rossi, 1998) & (Williams \& Katz, 2001) \\
\hline Perencanaan & $\begin{array}{l}\text { a. Definisi masalah atau } \\
\text { perumusan pertanyaan } \\
\text { penelitian } \\
\text { b. Indentifikasi kerangka } \\
\text { partisipan } \\
\text { c. Indentifikasi moderator } \\
\text { d. Membangkitkan dan uji coba } \\
\text { panduan wawancara } \\
\text { e. Merekrut partisipan }\end{array}$ & $\begin{array}{ll}\text { a. } & \text { Perencanaan: } \\
\text { - } & \text { Menentukan tujuan (Isu } \\
& \text { umum dan spesifik, tujuan } \\
& \text { FG, informasi yang } \\
& \text { diharapkan, sumber } \\
& \text { informasi) } \\
\text { - } & \text { Menentukan partisipan } \\
\text { - } & \text { Menentukan fasiltator } \\
\text { - } & \text { Mereview isu dan } \\
& \text { menyusun agenda (panduan } \\
\text { pelaksanaan FG) } & \text { Mereview persiapan } \\
& \text { khusunya bagi } \\
& \text { penanggungjawab perekam } \\
\text { data } & \\
\text { - Menyiapkan fasilitas } \\
\text { (lokasi, setting ruangan, } \\
\text { dan peralatan) }\end{array}$ & $\begin{array}{ll}\text { a. } & \text { Fokus pada tujuan } \\
\text { penelitian } \\
\text { b. Memilih moderator } \\
\text { c. Memilih dan merekrut } \\
\text { partisipan }\end{array}$ \\
\hline $\begin{array}{l}\text { Palaksanaan } \\
\text { diskusi }\end{array}$ & $\begin{array}{l}\text { f. Melakukan diskusi } \\
\text { g. Analisis dan interpretasi data }\end{array}$ & $\begin{array}{ll}\text { b. } & \text { Pelaksanaan: } \\
\text { - } & \text { Menyampaikan tujuan dan } \\
& \text { agenda } \\
\text { - } & \text { Analisis konten } \\
\text { - } & \text { Finalisasi laporan }\end{array}$ & $\begin{array}{ll}\text { d. } & \text { Analisis } \\
& \text { penggunaan hasil }\end{array}$ \\
\hline Evaluasi & h. Menulis laporan & $\begin{array}{l}\text { c. Evaluasi: menyusun matriks } \\
\text { tindak lanjut perbaikan }\end{array}$ & \\
\hline
\end{tabular}

Tabel 3. Penerapan FG dalam berbagai penelitian

\begin{tabular}{|c|c|c|c|c|c|c|c|c|c|c|}
\hline \multirow[b]{2}{*}{ No } & \multirow[b]{2}{*}{ Peneliti } & \multirow[b]{2}{*}{ 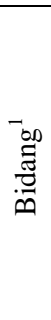 } & \multicolumn{3}{|c|}{ Tujuan } & \multicolumn{4}{|c|}{ Partisipan } & \multirow[b]{2}{*}{ 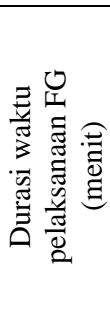 } \\
\hline & & & 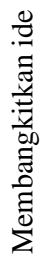 & 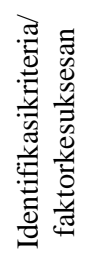 & 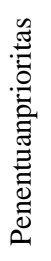 & $\begin{array}{l}\frac{\tilde{\sigma}}{\Xi} \\
\stackrel{\Xi}{\Xi} \\
\stackrel{\text { II }}{\approx}\end{array}$ & 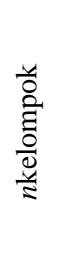 & 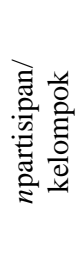 & $\begin{array}{l}\text { Bentuk pengelompokan } \\
\text { berdasarkan }\end{array}$ & \\
\hline 1 & (Nielsen, 2013) & 1 & & & $\bullet$ & 53 & 5 & $3-16$ & $\begin{array}{l}\text { Lokasi tempat tinggal } \\
\text { pelanggan }\end{array}$ & \\
\hline 2 & (Larasati, dkk, 2013) & 2 & & $\bullet$ & & 43 & 6 & $7-21$ & Program studi & \\
\hline 3 & (Einasto, 2014) & 2 & & $\bullet$ & & 15 & 2 & $7-8$ & $\begin{array}{l}\text { Program pendidikan (S1 } \\
\text { dan S2, dan S3) dan dosen }\end{array}$ & \\
\hline 4 & (Morris, dkk., 2006) & 2 & $\bullet$ & & & 60 & 10 & & $\begin{array}{l}\text { Kategori penanganan } \\
\text { pasien diabetes tipe } 1\end{array}$ & $90-120$ \\
\hline 5 & (Simigiu, 2014) & 1 & & $\bullet$ & & 51 & 5 & $6-15$ & $\begin{array}{l}\text { Kelompok usia (remaja } \\
\text { dan dewasa) dan profesi }\end{array}$ & \\
\hline 6 & (Kellogg, dkk., 2007) & 3 & $\bullet$ & & & 200 & 19 & $8-23$ & $\begin{array}{l}\text { Lokasi pelaksanaan } \\
\text { program }\end{array}$ & 90 \\
\hline
\end{tabular}

Penelitian terdahulu penggunaan FG untuk pemecahan masalah telah banyak dilakukan di berbagai bidang yaitu kesehatan (Nielsen, 2013; Simigiu, 2014), pendidikan (Morris, dkk., 2006; Larasati, Chisbiyah \& Hidayati, 2013; Einasto, 2014), dan lingkungan
(Kellogg, dkk., 2007). Berdasarkan analisis data sekunder dari beberapa jurnal (Tabel 3), ditemukan bahwa penggunaan FG bertujuan untuk membangkitkan ide, identifikasi kriteria atau faktor kesuksesan, dan penentuan prioritas. Partisipan pada 
penelitian tersebut bersifat homogen berdasarkan profesi, lokasi tempat tinggal, lokasi pelaksanaan program, dan lain-lain. Jumlah partisipan per kelompok bervariasi yaitu paling sedikit 3 partisipan dan ada yang mencapai 23 partisipan dalam satu kelompoknya. Jumlah partisipan pada penelitian tersebut pada umumnya jumlahnya cukup banyak sehingga dibagi menjadi beberapa kelompok FG sesuai dengan konteks permasalahan yang dipecahkannya.

\section{Metodologi}

Model logika penelitian penentuan kriteria pengukuran IKU penyelenggaraan diklat berbasis kompetensi disajikan seperti pada Gambar 1. Target output penelitian bagian awal ini adalah daftar kriteria yang dijadikan acuan untuk menentukan diklat yang masuk kategori diklat berbasis kompetensi. Sedangkan outcome penelitian yaitu terwujudnya pengembangan SDM berbasis kompetensi dan berdasarkan pada kebutuhan pemangku kepentingan.

Tahapan penelitian penentuan kriteria pengukuran IKU penyelenggaran diklat berbasis kompetensi mengacu pada tahapan yang telah dikembangakan para peneliti di atas terdiri dari tahap perencanaan, pelaksanaan, dan evaluasi pasca pelaksanaan FG (Gambar 2). Penelitian dilaksanakan pada bulan Oktober - Desember 2015.

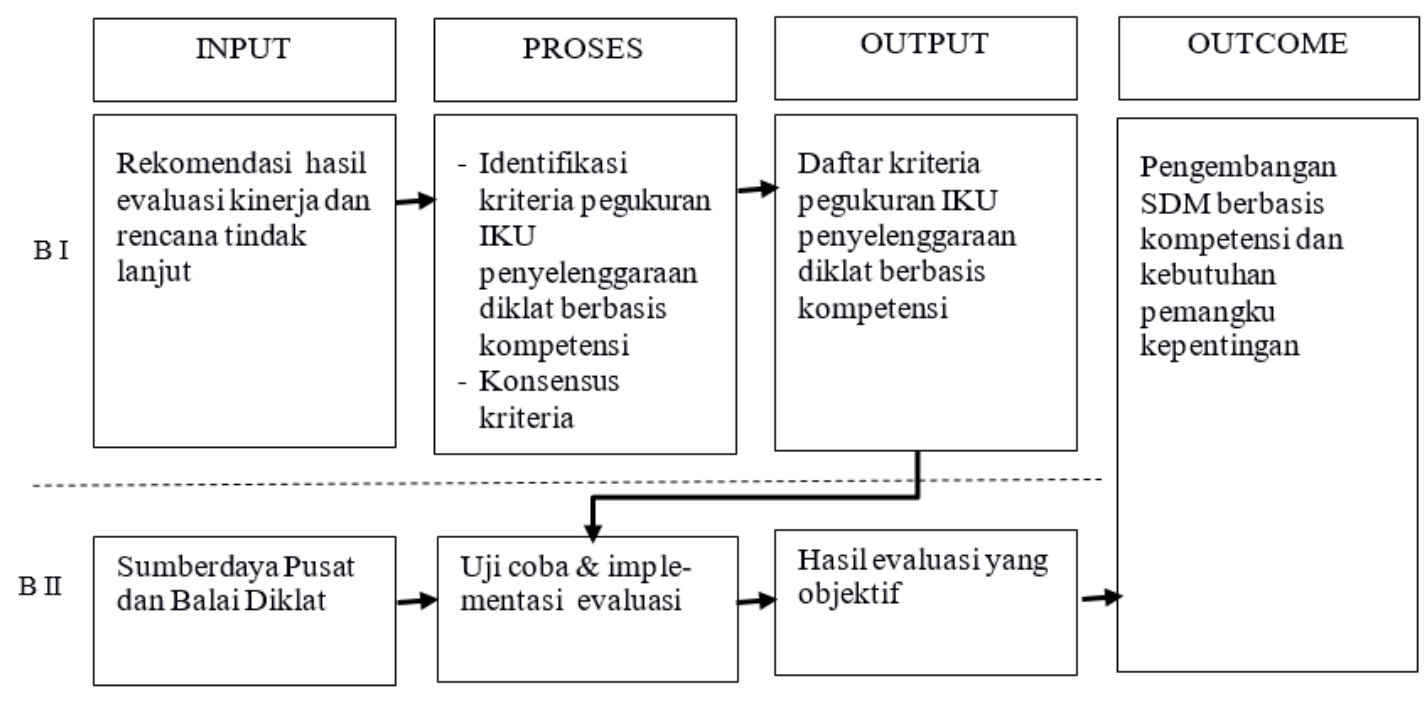

Gambar 1. Model logika penelitian

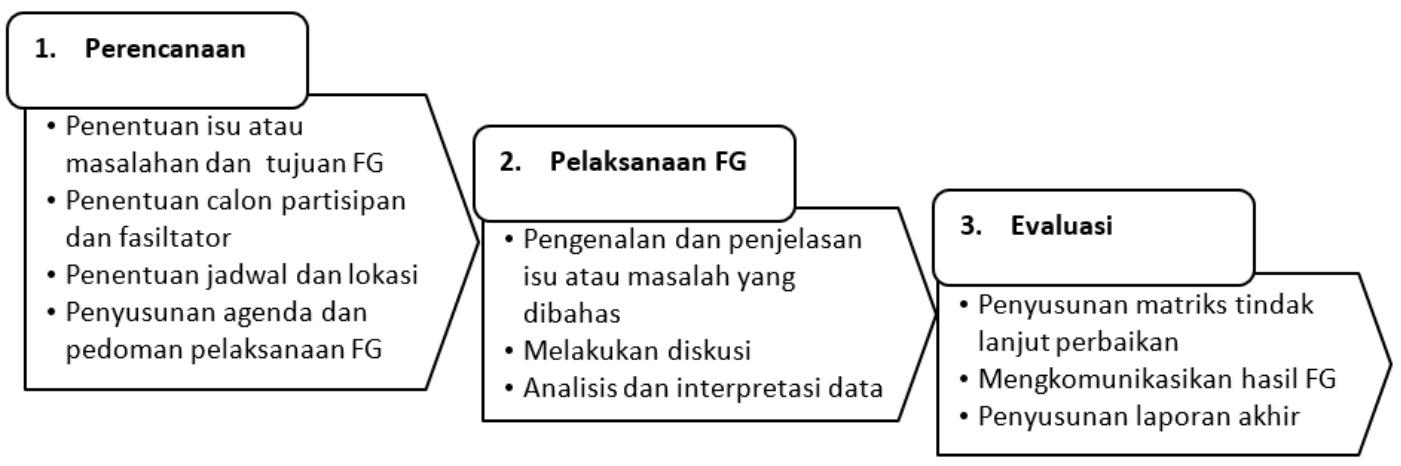

Gambar 2. Tahapan pelaksanaan FG 
Tahap perencanaan dilakukan sebelum pelaksanaan FG terdiri dari: a) Penentuan isu atau masalah capaian kinerja utama organisasi yang menjadi prioritas untuk dicarikan solusinya. Salah satu isu yang dibahas adalah penyelenggaraan diklat berbasis kompetensi. Untuk memperdalam masalah dan memudahkan perumusan tujuan, peneliti menggunakan sumber data sekunder yang berasal dari peraturan perundangundangan terkait, buku teks, dan artikel ilmiah. b) Penentuan calon partisipan sangat terkait dengan masalah yang dibahas. Terkait dengan masalah dan tujuan penelitian, maka calon partisipannya adalah pemangku kepentingan internal (widyaiswara dan pengelola evaluasi kinerja penyelenggaraan diklat) dari Pusat dan Balai Diklat di lingkungan Badan Diklat ESDM sebanyak 12 partisipan. c) Penyusunan pedoman FG untuk memudahkan fasilitator dan perekam data (recorder) memandu diskusi dan mengumpulkan data primer dari partisipan. Pedoman FG berisi latar belakang masalah, tujuan, dan daftar pertanyaan.

FG penentuan kriteria IKU penyelenggaraan diklat berbasis kompetensi terdiri dari satu kelompok dan dilaksanakan pada bulan November 2015. Proses pelaksanaan FG adalah penyampaian agenda, pengantar pengenalan dan penjelasan isu atau masalah serta target output yang diharapkan dari pelaksanaan diskusi. Selanjutnya sesi diskusi oleh para partisipan dipandu oleh failitator dan perekam data. Data primer hasil diskusi dianalisis dan diinterpretasikan, dan hasilnya dikonsensuskan oleh para partisipan sebelum diskusi ditutup. Evaluasi pasca pelaksanaan diskusi yaitu menyusun matrik tindak lanjut perbaikan dan hasilnya dikomunikasikan kepada pemangku kepentingan internal dan partisipan.

\section{HASIL DAN PEMBAHASAN}

Berikut ini disajikan hasil dan pembahasan pelaksanaan FG secara kronologis berdasarkan tahapan pelaksanaan FG. Hasil dan pembahasan diawali dengan paparan pengantar review IKU penyelenggaraan diklat berbasis kompetensi dan peraturan perundang-undangan tentang diklat berbasis kompetensi oleh fasilitator setelah sesi formal pembukaan diskusi.

\section{IKU penyelenggaraan diklat berbasis kompetensi}

Penyelesaian berbagai masalah strategis sektor ESDM memerlukan dukungan sumber daya manusia (SDM) yang kompeten dan profesioanl sesuai dengan jenjang kualifikasinya. Untuk mewujudkan SDM

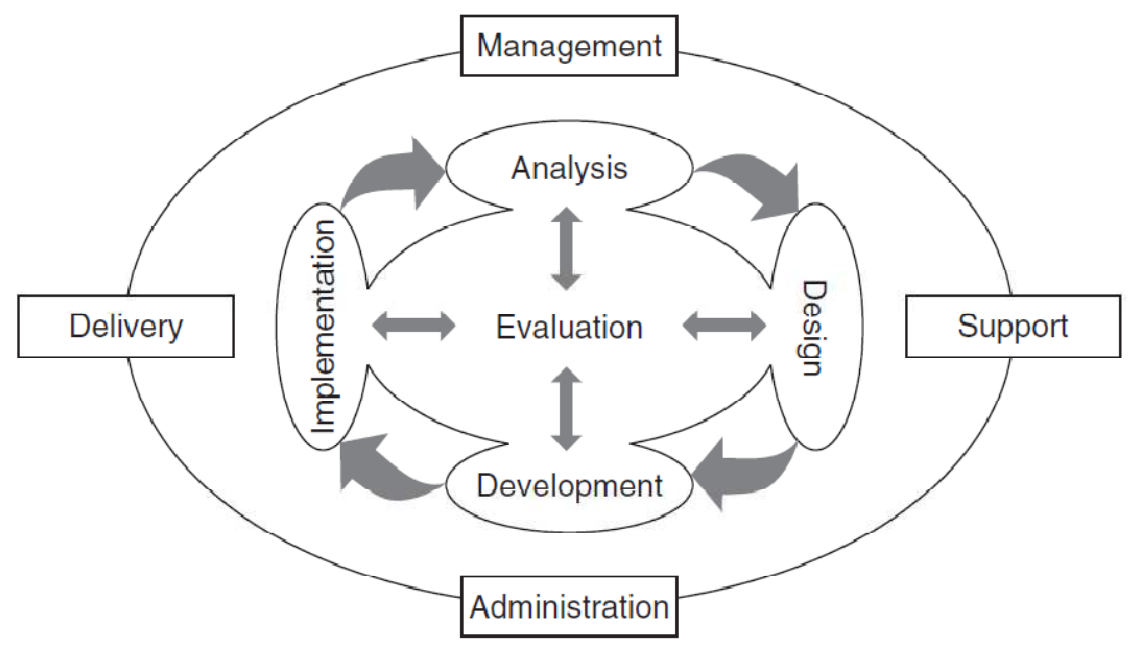

Gambar 3. Model sistem diklat ADDIE (Allen, 2006) 
yang kompeten dan profesional, maka rencana strategis jangka menengah (20152019) yang dirumuskan bertujuan untuk mewujudkan SDM kompeten dalam peningkatan ketahanan energi dan mineral yang berwawasan lingkungan di sektor ESDM. Tujuan strategis dicapai melalui beberapa sasaran strategis yang mewakili dari empat perspektif balaced scorecard yaitu pemangku kepentingan, pelanggan, proses internal, dan pembelajaran dan pertumbuhan. Sasaran strategis dari perspektif pemangku kepentingan yaitu pengembangan SDM berbasis kompetensi dan untuk mengevalusi capaian kinerjanya menggunakan alat ukur IKU penyelenggaraan diklat berbasis kompetensi.

Diklat berbasis kompetensi mengacu pada Permenakertrans No. 8 Tahun 2014 tentang Pedoman Penyelenggaraan Pelatihan Berbasis Kompetensi adalah pelatihan kerja yang menitikberatkan pada penguasaan kemampuan kerja yang mencakup pengetahuan, keterampilan, dan sikap sesuai dengan standar yang ditetapkan dan persyaratan di tempat kerja. Prinsip pelatihan berbasis kompetensi yaitu: a) dilaksanakan berdasarkan identifikasi kebutuhan pelatihan dan/atau standar kompetensi, b) adanya pengakuan terhadap kompetensi yang telah dimiliki, berpusat kepada peserta pelatihan dan bersifat individual, multi-entry/multi-exit, yang memungkinkan peserta untuk memulai dan mengakhiri program pelatihan pada waktu dan tingkat yang berbeda, sesuai dengan kemampuan masing-masing peserta pelatihan, c) peserta pelatihan dinilai berdasarkan pencapaian kompetensi sesuai standar kompetensi, dan d) dilaksanakan oleh lembaga pelatihan yang terregistrasi atau terakreditasi nasional.

\section{Penentuan kriteria pengukuran}

Berdasarkan hasil diskusi sesi pertama dengan para pemangku kepentingan internal, telah berhasil diidentifikasi daftar sementara kriteria pengukuran IKU penyelenggaraan diklat berbasis kompetensi sebayak sepuluh yaitu standar kompetensi, analisis kebutuhan diklat, standar kurikulum, modul, peralatan praktek, pedoman penyelenggaraan, modul uji, uji kompetensi, evaluasi penyelenggaraan dan pasca diklat, kesesuaian kompetensi widyaiswara dengan kebutuhan diklat, dan kompetensi tenaga penyelenggaraan diklat. Daftar sementara tersebut didiskusikan lagi pada sesi kedua. Hasil diskusi sesi kedua adalah penyederhanaan kriteria dari sepuluh menjadi enam kriteria berdasarkan pertimbangan kesiapan sumber daya yang dimiliki pemangku kepentingan saat ini. Pada sesi kedua diskusi juga dilakukan analisis dengan mengelompokkannya ke dalam model generik sistem diklat. Model sistem diklat yang digunakan yaitu model generik sistem diklat ADDIE (analysis, design, develop, implement, dan evaluate) seperti disajikan pada Gambar 3.

Mengacu pada model generik ADDIE, maka hasil pengelompokkan kriteria yang telah dirangkum oleh fasilitator dan perekam data (Tabel 4) disampaikan kembali kepada partisipan untuk dijadikan bahan konsensus. Kriteria yang dikonsensuskan bersama oleh

Tabel 4. Kriteria pengukuran diklat berbasis kompetensi

\begin{tabular}{clll}
\hline No. & Tahapan Diklat & & \multicolumn{1}{c}{ Kriteria } \\
\hline 1 & Analisis & a. & Analisis kebutuhan diklat \\
2 & Desain & b. & Standar kurikulum silabus \\
3 & Pengembangan & c. & Modul \\
& & d. & Pedoman penyelenggaraan \\
& & & diklat \\
4 & Implementasi & & \\
5 & Evaluasi & e. & Evaluasi widyaiswara \\
& & f. & Evaluasi penyelenggaraan diklat \\
\hline
\end{tabular}


para pratisipan merepresentasikan pemangku kepentingan internal masih di bawah kriteria persyararatan diklat berbasis kompetensi dipersyaratkan oleh Kementerian Tenaga Kerja dan Transmigrasi (Permenakertrans No. 8 Tahun 2014 tentang Pedoman Penyelenggaraan Pelatihan Berbasis Kompetensi). Terkait dengan implementasi enam kriteria yang telah dikonsensuskan, pada umumnya seluruh partisipan menyampaikan pendapatnya bahwa perlu dilakukan uji coba untuk melihat sejauhmana kesiapan sumber daya yang dimiliki pemangku kepentingan internal dalam menjalankannya. Adapun untuk mengukur diklat yang telah memenuhi persyaratan diklat berbasis kompetensi, maka pada tahap awal penerapannya masih dilakukan dengan menunjukkan bukti tersedianya dokumendokumen tersebut. Sedangkan pengukuran aspek mutu dokumen dilakukan pada tahap berikutnya setelah penerapan tahap pertama dianggap berhasil.

Sistem penyelenggaran diklat berbasis kompetensi harus didasarkan pada pemenuhan kebutuhan yang dirasakan organisasi dan individu masih memiliki kesenjangan kompetensi untuk meningkatkan kinerja. Untuk mendapatkan gambaran ini maka dilakukan analisis kebutuhan diklat. Analisis kebutuhan diklat (AKD) adalah metode sistematis untuk menentukan apa penyebab rendahnya kinerja yang dirasakan saat ini terhadap kinerja yang diharapkan. Hasil AKD menjadi bahan masukan tahap pengembangan untuk menyusun formula strategi instruksional agar mencapai tujuan diklat. Outputnya tahap pengembangan berupa dokumen yang berisi konten, metode, peralatan dan media, pedoman, dan lain-lain. Tahap akhir sistem penyelenggaraan diklat berbasis kompetensi adalah evaluasi (Blanchard and Thacker, 2013). Evaluasi yang dilakukan baru meliputi evaluasi widyaiswara dan evalausi penyelenggaraan diklat meliputi evalausi kepuasan peserta dan evaluasi hasil belajar peserta diklat. Evaluasi kepuasan peserta pelatihan dan pembelajaran adalah evaluasi outcome jangka pendek yang sudah umum dilakukan oleh lembaga pelatihan. Aspek yang diukur pada evaluasi kepuasan meliputi fasilitas, jadwal pelaksanaan, sajian makanan, sarana pembelajaran, dan bahan ajar. Peserta memberikan penilaian terhadap kinerja penyelenggaraan pelatihan pada sesi akhir sebelum penyelenggaraan pelatihan ditutup. Sedangkan evaluasi pembelajaran untuk mengetahui efektifitas diklat dalam meningkatkan kompetensi peserta dengan membandingan ujian sebelum diklat (pre test) dan ujian setelah selesai seluruh diklat (post test). Hasil pre test dan post test diklat yang satu (kelompo kontrol) disarankan juga untuk dibandingkan dengan hasil pre test dan post test lainnya (kelompok pembanding) (Kirkpatrick, 1998). Dari hasil diskusi juga terungkap, bahwa evaluasi pasca diklat telah dilakukan oleh pemangku kepntingan namun baru terbatas untuk diklat strategis bidang ESDM.

\section{SIMPULAN}

Perumusan IK harus memenuhi seluruh kriteria mutu CREAM agar indikator tersebut dapat diimplementasikan dengan baik dan memberikan banyak informasi bagi pengambil keputusan untuk menentukan intervensi perbaikan pada sebuah program. IKU penyelenggaraan diklat berbasis kompetensi yang telah dirumuskan sejatinya telah memenuhi kriteria CREAM. Namun setelah diimpelemnatasikan dan direview, ditemukan adanya banyak penafsiran pengukuran oleh masing-masing pemangku kepentingan internal. Berdasarkan hasil diskusi, diperoleh konsensus enam kriteria pengukuran IKU penyelenggaraan diklat berbasis kompetensi. Tahap pertama uji coba kriteria dilakukan dengan mengukur diklat yang telah memenuhi kriteria berbasis kompetensi berdasarkan ketersediaan dokumen. Untuk selanjutnya dapat ditingkatkan dengan mengukur aspek 
mutunya. Penggunaan FG pada penyelesaian masalah ini telah terbukti efektif dalam membangkitkan ide dan membangun partisipasi serta keterlibatan pemangku kepentingan internal untuk mendukung tujuan dan sasaran strategis organisasi. Untuk mengoptimalkan pelaksanaan FG dalam mengumpulkan, manganalisis, dan menyajikan data primer, perlu dilakukan perencanaan FG yang baik khususnya dengan penajaman substansi isu atau masalah yang akan dikaji dan penentuan partisipan yang mengerti substansi isu atau masalah tersebut. Adapun kendala teknis pelaksanaan FG adalah memastikan agar partisipan yang mengerti permasalahan dapat hadir pada pelaksanaan diskusi.

\section{DAFTAR PUSTAKA}

Allen, W.C. (2006). "Overview and evolution of the ADDIE training system". Advances in Developing Human Resources, Vol. 8 (4), pp. 430 - 441.

Bader, G.E.; Rossi, C.A. (1998). Focus Groups: A Step-ByStep Guide. The Bader Group.

Blanchard, P.N.; Thacker, J.W. (2013). Effective Training: System, Strategies, and Practice. Fifth Edition. Essex: Pearson Education.

Einasto, O. (2014). "E-service Quality Criteria in University Library: A Focus Group Study". Procedia - Social and Behavioral Sciences. Elsevier B.V., Vol. 147, pp. 561 566.

Kellogg, W.A.; O’Brien, K.; Robey, C.; Toth, K. (2007) "The Use of Focus Groups for Design and Implementation of Collaborative Environmental Administrative Programs: A Comparison of Two StateLevel Processes in Ohio". Environmental Practice, Vol. 9 (3), pp. $166-178$.

Kirkpatrick, D.L. (1998). Evaluating Training Programs: The Four Levels. Second Edi. San Fransisco: BerrettKoehler Publishers.

Kusek, J.Z.; Rist, R.C. (2004). Ten steps to a results-based monitoring and evaluation system: a handbook for development practitioners. Washington: The International Bank for Reconstruction and Development/The World Bank.

Larasati, A.; Chisbiyah, L.A.; Hidayati, L. (2013) "Penerapan Focus Group Discussion untuk Mengevaluasi Kualitas Layanan Jurusan Teknologi Industri'. Teknologi dan Kejuruan, Vol. 36(2), pp.: 197 204.

Morris, M.; Johnson, A.; Booker, S.; Gunnery, R.; Meek, P. (2006). "Designing an education programme for type 1 diabetes: A focus group study". Journal of Diabetes Nursing, Vol. 10 (10), pp. $393-399$.

Nielsen, M. (2013). A Focus Group Study of Consumer Priorities for Pain Management Resources in NSW.
Parmenter, D. (2007). Key Performance Indicators: Developing, Implementing, and Using Winning KPIs, John Wiley \& Sons. New Jersey: John Wiley \& Sons. doi: 978-0470545157.

Simigiu, A. (2014). "Investigating the views of civil society on early pregnancy through the focus group method", Procedia - Social and Behavioral Sciences. Elsevier B.V., Vol. 127, pp. $219-224$.

Smithson, J. (2000). "Using and analysing focus groups: limitations and possibilities." International Journal Social Research Methodology, Vol. 3(2), pp. 103-119.

Stewart, D.W.; Shamdasani, P.N. (1990). Focus groups: Theory and practice, Applied Social Research Methods Series. Edited by K. A. Clark. California: SAGE Publications.

Williams, A.; Katz, L. (2001) "The use of focus group methodology in education: Some theoretical and practical considerations". International Electronic Journal for Leadership in Learning, Vol. 5 (3), pp: .... 